\title{
Non-descent vaginal hysterectomy in women with previous caesarean section scar: our experience
}

\author{
G. D. Maiti ${ }^{*}$, Ashok Pillai ${ }^{2}$, Tony Jose ${ }^{1}$, P. R. Lele ${ }^{1}$
}

\begin{abstract}
${ }^{1}$ Department of Obstetrics and Gynaecology, Command Hospital (EC), WBUHS, Kolkata, West Bengal, India
${ }^{2}$ Department of Obstetrics and Gynaecology, Medical Trust Hosptal, MG Road, Kochi, Kerala, India
\end{abstract}

Received: 04 April 2018

Accepted: 30 April 2018

\section{*Correspondence:}

Dr. G. D. Maiti,

E-mail: gdmaiti@rediffmail.com

Copyright: (c) the author(s), publisher and licensee Medip Academy. This is an open-access article distributed under the terms of the Creative Commons Attribution Non-Commercial License, which permits unrestricted non-commercial use, distribution, and reproduction in any medium, provided the original work is properly cited.

\begin{abstract}
Background: Hysterectomy is one of the common gynaecological major surgeries performed worldwide. In spite of technological advancement with laparoscopic and robotic hysterectomy conventional hysterectomy through vaginal route of nonprolapse uterus popularly known as, Non-Descent Vaginal Hysterectomy (NDVH) remains a justifiable cost effective, cosmetically appealing option especially in resource-crunched developing country. NDVH in post caesarean scarred uterus too a technically challenged procedure requiring skills and expertise.

Assessment of technical feasibility and safety of non-descent vaginal hysterectomy in women with previous caesarean section scar were studied.

Methods: The study was a prospective observational study of 72 patients with LSCS scar requiring hysterectomy for benign conditions were selected based on the inclusion and exclusion criteria carried out from June 2012 to May 2017. Operating time, blood loss, surgical techniques, intra/postoperative challenges, conversion to laparotomy or laparoscopic assistance and length of hospital stay were recorded for each case. Patients were followed up till 03 months of surgery.

Results: Vaginal hysterectomy was successful in all cases. Morcellation, bisection or myomectomy, were done in $86 \%$ cases. Two patients had bladder injury, which was repaired vaginally, two cases required support of laparoscopy. No patients needed blood transfusion. None of the patients were converted to laparotomy.

Conclusions: Vaginal hysterectomy is a safe and effective procedure for benign non-prolapsed uteri in women with previous caesarean section scar when uterine size is less than 14 weeks. Standby operating laparoscopy provides added advantages to surgeon in doubtful or difficult cases to avoid conversion laparotomy.
\end{abstract}

Keywords: Hysterectomy, NDVH, Post LSCS scarred uterus, Vaginal hysterectomy

\section{INTRODUCTION}

Hysterectomy is the surgical removal of the uterus, being the commonest major gynecological surgeries done worldwide. ${ }^{1}$ Conventionally and historically vaginal hysterectomy is done in cases of utero vaginal prolapse and abdominal route used to be performed in most of other indications. ${ }^{2}$ Subsequently, hysterectomy through vaginal route for nonprolapse uterus popularly known as,
"Non Descent Vaginal Hysterectomy" (NDVH) has proved to be feasible, safe, cost effective and justifiable option in comparison to abdominal route even in large size uterus by various studies. ${ }^{3-5}$

In the last two decades, laparoscopic hysterectomy has emerged as the most alternative method, is associated with higher costs, skilled surgeon, specially trained paramedical staff with longer training curve, costly 
laparoscopic equipment, longer duration of surgery and relatively higher major risks. ${ }^{6}$ In present days practice, cases of hysterectomy with previous caesarean section scar expanding due to higher caesarean section rates, which has been a relative contraindication for NDVH in fear of encountering adhesion and injury to adjacent organs specially to urinary bladder. ${ }^{7,8,9}$ The size of the uterus, nulliparity, previous pelvic surgery or lower segment caesarean section (LSCS), pelvic adhesions and endometriosis are the commonly cited limitations for vaginal hysterectomy. ${ }^{10}$ But now vaginal hysterectomy in larger sized uterus is facilitated by bisection, myomectomy, debulking, coring and clamp less approach etc. $^{11}$

The present study is undertaken to study safety and feasibility of NDVH in cases with previous scarred uterus namely previous pelvic surgery or lower segment caesarean section as an indication for non-descent vaginal hysterectomy. The aim of the study was to determine the role, feasibility and safety of non-descent vaginal hysterectomy in women with previous caesarean section scar. The objectives of the present study were to determine: -

a) Duration of surgery and conversion or supplementation with General anaesthesia.

b) Operative Blood loss requiring blood transfusion.

c) Intra op and post op complications in form of:

- Intra operative conversion to laparotomy or Laparoscopic assisted completion for technical difficulty

- Intra operative Injury to bladder, intestine, rectum or ureters

- Post-operative laparotomy or laparoscopy for hemorrhagic complication or other complication.

- Post-operative febrile morbidity, wound infection

- Prolong hospital stay

\section{METHODS}

This was a prospective observational study carried out in tertiary and Zonal level hospitals from Jun 2012 to May 2017.

A total of 72 cases were studied

\section{Inclusion criteria}

- Previous pelvic surgery- one, two or three caesarean sections

- Uterine size less than 14 weeks

- Benign uterine condition like fibroid uterus or DUB

- Absence of any degree of utero vaginal prolapse

\section{Exclusion criteria}

- Presence of adnexal mass-large ovarian cyst/ endometriosis

- Uterine size greater than 14 weeks
- Uterine malignancies

- Absence of uterine mobility

Seventy-two patients requiring hysterectomy for benign conditions and who had a history of previous caesarean section were selected for the study. They all underwent routine preoperative investigations to rule out any comorbidity. They also underwent ultrasound pelvis to rule out any other pelvic pathology and for confirmation of uterine size and site of fibroids if any.

\section{Surgical Technique}

All were done under spinal anesthesia except cases requiring laparoscopy or ineffective SA where GA was supplemented or converted. Examination under anaesthesia was done to confirm extent of mobility, size of uterus, absence of adnexal mass and degree of descent. The Para cervical tissues were infiltrated with 1:200,000 adrenaline or normal saline where adrenaline was contraindicated. A transverse incision was given on the vesicouterine junction and the bladder pushed up by blunt dissection placing pressure mostly on cervix.

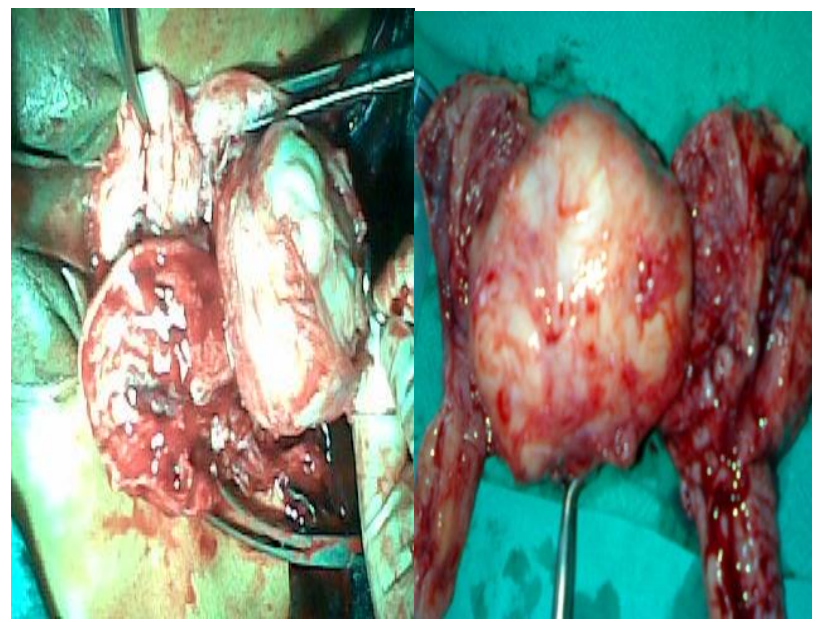

Figure 1: Cases of NDVH with large myomas being managed with bisection and Myomectomy.

Wherever the bladder was found densely adherent to the anterior wall of uterus, cervix or difficulty encountered in separating, either sharp dissection or posterior/lateral approach through unilateral or bilateral window on broad ligaments were undertaken. In most cases, the adhesions were found to be less dense on both sides of the midline. A posterior incision was then given, and the POD opened. The first clamp included part of the uterosacrals and the Mackenrodts ligament. The second clamp took the rest of the uterosacral ligament. Efforts were made to open anterior pouch before the uterine artery clamps were placed. However, wherever difficulty was encountered opening of anterior pouch were undertaken subsequently. The third clamp was placed over the uterine artery along with the cut edge of the anterior and posterior peritoneum. 


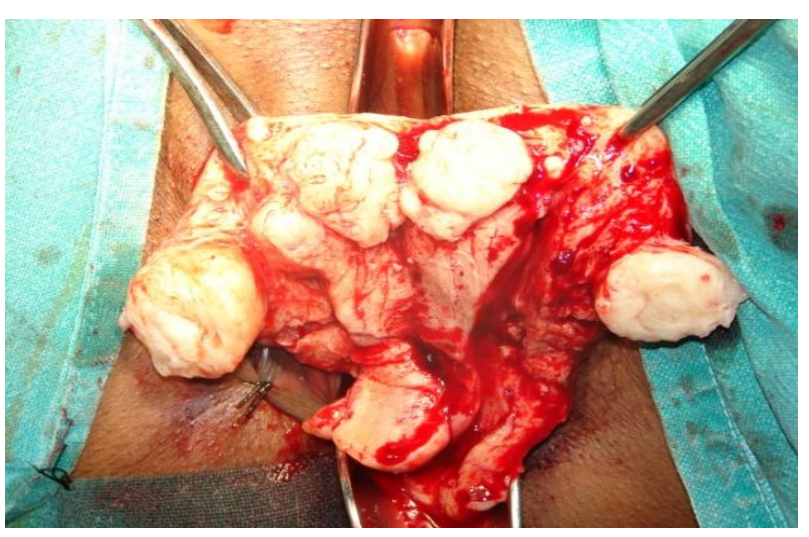

Figure 2: Case of previous 1 LSCS with multiple myomas managed with NDVH.

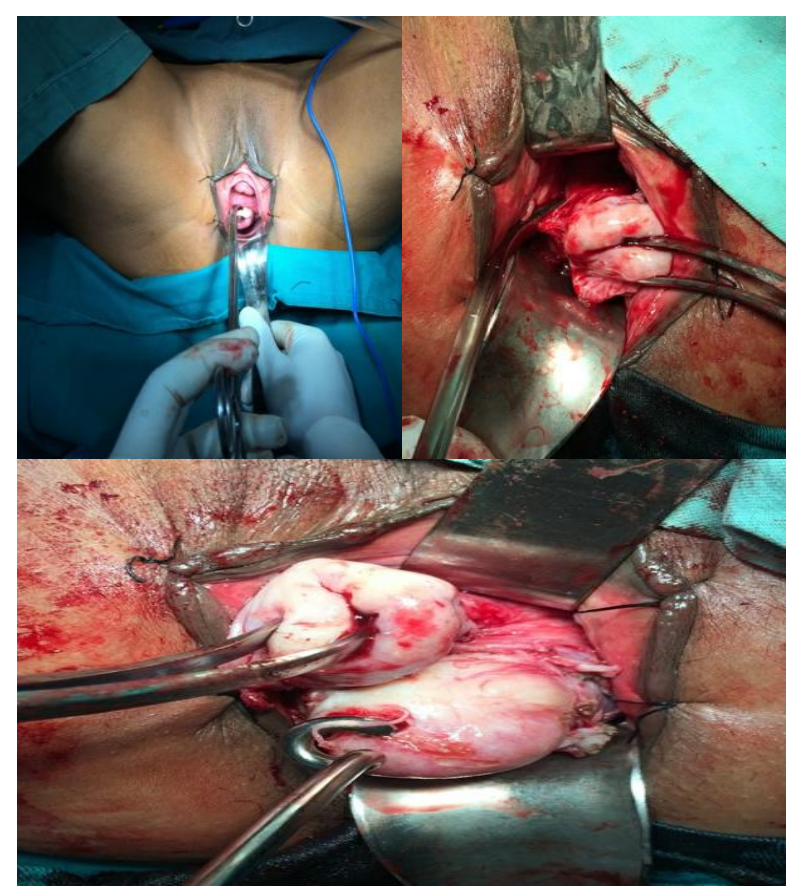

Figure 3: Previous 2 LSCS with false broad ligament fibroid being delivered using myoma screw myomectomy done to enhance operating space.

After the uterine arteries were clamped, depending on the size of the uterus and availability of lateral space, debulking of uterus by using various methods including bisection of uterus, myomectomy, morcellation by coring or wedge resection were done to address upper pedicles.

For bisection the cervix was held on either side and uterus cut sagittally using a knife keeping guard of bladder and rectum. The incision was further extended posteriorly followed by anteriorly till bisection was complete. One hemi- uterus was then pushed inside the pelvis to avail space to deal upper pedicles containing round ligament, fallopian tube, ovarian ligament or infundibulopelvic ligament where ovaries need to be removed. This was repeated on the other half of the uterus. Haemostasis was ensured.
The vault was then closed with continuous suture using No1/1-0 delayed absolvable suture.

All patients were managed postoperatively with IV fluid, prophylactic antibiotics, analgesics as per hospital protocol for major surgery and discharged on 3-5 days post op day depending on individual recovery. Followed up on monthly basis till 03 months.

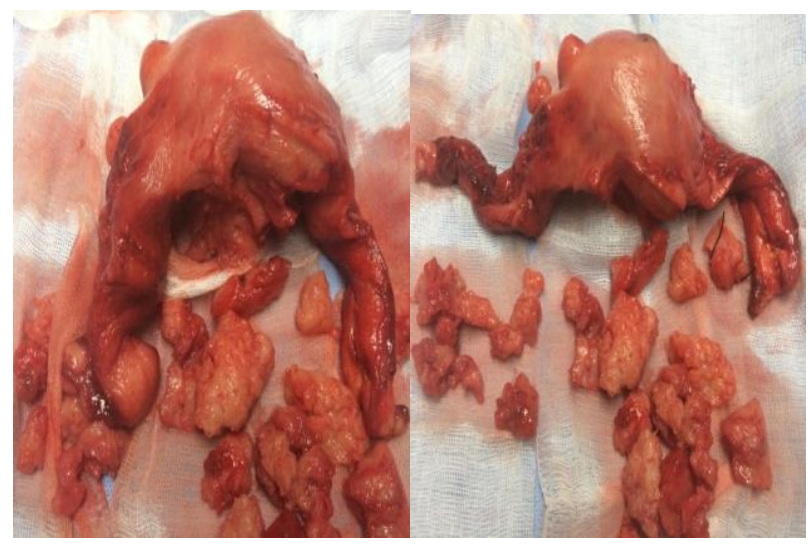

Figure 4: Previous 2 LSCS with 14 wks size uterus bisection with morcellation done.

The following parameters were measured and recorded.

a) Blood loss:

- Measured blood in suction bottle

- Counted soaked abdominal swab. $24 \mathrm{~cm}$ X $24 \mathrm{~cm}$ size swabs were used in all the surgeries. Estimated blood was $20 \mathrm{ml}$ if swab was half soaked and $40 \mathrm{ml}$ when completely soaked.

b) Intra op and post op complications

- Conversion to laparotomy (TAH) or Laparoscopic assisted completion.

- Post-operative exploration/laparoscopy for hemorrhagic complication

- Injury to bladder, intestine, rectum or ureters

- Febrile morbidity - Temp more than $100.4 \mathrm{~F}$ on two occasions six hrs. apart, after the first $24 \mathrm{hrs}$. of surgery.

- Any other symptoms like post op trenesmus, diarrhoea, ileus etc.

c) Duration of surgery and conversion or supplementation with General anaesthesia

d) Duration of hospital stay

e) Any complication up to 03 months of follow up

\section{RESULTS}

The results were analysed using SPSS 18 and qualitative variables were presented as frequencies and percentages.

The salient features observed from the data obtained are enumerated in the succeeding paragraphs. The maximum number of patients were in the 40 to $49 \mathrm{yrs}$ age group $(65.5 \%)$. 
Table 1: Age wise distribution of cases $(n=72)$.

\begin{tabular}{ll} 
Age Group & Frequency $(\%)$ \\
\hline $30-39$ & $06(8.6 \%)$ \\
\hline $40-49$ & $47(65.5 \%)$ \\
$>49$ Years & $19(25.8 \%)$ \\
\hline
\end{tabular}

There were 09 (12.5\%) cases who have had one delivery, whereas the remaining $63(87.5 \%)$ cases were multipara cases of which 43 cases $(59.7 \%)$ had 2 caesarean sections without vaginal deliveries. The remaining 20 cases had vaginal delivery before or after caesarean delivery (VBAC).

Table 2: Parity wise distribution of cases $(n=72)$.

\begin{tabular}{|c|c|c|c|c|}
\hline Parity & \multicolumn{4}{|c|}{ Frequency (\%) } \\
\hline Primipara & \multicolumn{4}{|c|}{$09(12.5 \%)$} \\
\hline \multirow[t]{2}{*}{ Multipara } & \multirow[t]{2}{*}{$\begin{array}{l}63 \\
(87.5 \%)\end{array}$} & $\begin{array}{l}\text { Previous } \\
2 \text { LSCS }\end{array}$ & VBAC & $\begin{array}{l}\text { Vaginal } \\
\text { birth } \\
\text { before } \\
\text { LSCS }\end{array}$ \\
\hline & & $\begin{array}{l}43 \\
(59.7 \%)\end{array}$ & $\begin{array}{l}15 \\
(20.8 \%)\end{array}$ & $\begin{array}{l}05 \\
(6.9 \%)\end{array}$ \\
\hline
\end{tabular}

The most common indication for undergoing vaginal hysterectomy was dysfunctional uterine bleeding which accounted for $43 \%$, followed by fibroid uterus which accounted for $30.5 \%$ of the cases. Maximum number of 42 cases $(58.3 \%)$ was done with uterine size upto 8 weeks, followed by $15(20.8 \%)$ cases with size of $8-10$ wks. $6(8.3 \%)$ of cases were having maximum size of uterus of $12-14$ weeks. Only in 10 cases $(13.8 \%)$, the uterus could be removed out in toto. In 28 cases (38.9\%), the uterus was bisected to facilitate clamping of the upper pedicles.

Table 3: Indications for Hysterectomy $(n=72)$

\begin{tabular}{|ll|}
\hline Indication & Frequency $(\%)$ \\
\hline DUB & $31(43)$ \\
\hline Fibroid Uterus & $22(30.5)$ \\
\hline Adenomyosis & $09(12.5)$ \\
\hline $\begin{array}{l}\text { Endometrial } \\
\text { Hyperplasia }\end{array}$ & $10(13.8)$ \\
\hline
\end{tabular}

Table 4: Case distribution according to uterine size.

\begin{tabular}{|lll|}
\hline Uterine Size & No of cases & Percentage \\
\hline < 8 weeks & 42 & 58.3 \\
\hline $8-10$ weeks & 15 & 20.8 \\
\hline $10-12$ weeks & 9 & 12.5 \\
\hline$>12$ weeks & 6 & 8.3 \\
\hline
\end{tabular}

Enucleation of myoma was done in 10 (13.8\%) cases. Combination of techniques were undertaken in 16 $(22.2 \%)$ Morcellation/wedge resection was done in $8(11.1 \%)$ cases. Only NDVH was done in $57(79.2 \%)$ cases, while NDVH with bilateral salpingo-opherectomy was done in $09(12.5 \%)$ cases.

Tension free vaginal tape for associated stress urinary incontinence was done in $06(8.3 \%)$ cases. The longest operating time more than 120 min. were in 9 cases which included 02 bladder injury, 01 case of superficial rectal injury, 03 cases with 14 weeks size uterus with previous 2 LSCS, 02 cases requiring per operative diagnostic laparoscopy for confirmation of intraoperative haemorrhage.

Table 5: Surgical procedure/debulking undertaken.

\begin{tabular}{|c|c|c|}
\hline Procedure & Frequency & $\%$ \\
\hline Removal of Intact Uterus & 10 & 13.8 \\
\hline Bisection & 28 & 38.9 \\
\hline Myomectomy & 10 & 13.8 \\
\hline Morcellation & 8 & 11.1 \\
\hline Combination technique & 16 & 22.2 \\
\hline
\end{tabular}

Table 6: Adjuvant Procedures Done

\begin{tabular}{|ll|l|}
\hline Adjuvant Procedures & Frequency & $\%$ \\
\hline NDVH Only & 57 & 79.2 \\
\hline NDVH with BSO & 09 & 12.5 \\
\hline NDVH with TVTO-O/TOT & 06 & 8.3 \\
\hline
\end{tabular}

The blood loss ranged from 40 to $240 \mathrm{ml}$ with a mean loss of $100 \mathrm{ml}$. The average hospital stay was 04 days with the longest stay being 08 days. Two patients had bladder injury whilst separating the bladder, 01 had iatrogenic superficial rectal injury during posterior culdotomy. These were identified and repaired vaginally during the surgery. Eight patients had diarrhoea in the first forty-eight hours postop and were treated conservatively. Two cases required support of laparoscopy to exclude intraoperative haemorrhage.

Table 7: Duration of surgery.

\begin{tabular}{|lll|}
\hline Surgical time (Min) & Frequency & $\%$ \\
\hline$<60$ & 24 & 33.4 \\
\hline $60-90$ & 30 & 41.7 \\
\hline $90-120$ & 12 & 16.6 \\
\hline$>120$ & 6 & 8.3 \\
\hline
\end{tabular}

Table 8: Intraoperative blood loss.

\begin{tabular}{|lll|}
\hline Blood loss $(\mathrm{ml})$ & Frequency & $\%$ \\
\hline$<100$ & 28 & 38.8 \\
\hline $100-150$ & 35 & 52.7 \\
\hline$>150$ & 9 & 12.5 \\
\hline
\end{tabular}

Four patients developed vault granuloma, which were cauterized under anaesthesia. They presented with persistent spotting even after one month of surgery. Only one patient had UTI and febrile morbidity, which 
responded to antibiotics. None of the patients had to be converted to abdominal hysterectomy.

Table 9: Quality indicators.

\begin{tabular}{|ll|}
\hline Quality Indicators & Assessment \\
\hline Avg Operation Time & $58 \mathrm{Min}$ \\
\hline Avg Blood Loss & $100 \mathrm{Ml}$ \\
\hline Avg Hospital Stay & 4 Days \\
\hline
\end{tabular}

Table 10: Operative injuries and post-operative complications.

\begin{tabular}{|l|l|}
\hline Complications & Frequency \\
\hline Bladder injury & 02 \\
\hline Ureter injury & Nil \\
\hline Bowel injury & 01 \\
\hline Slipping of pedicle & Nil \\
\hline Febrile morbidity & One \\
\hline Assistance of laparoscopy & 02 \\
\hline Secondary haemorrhage & Nil \\
\hline UTI & One \\
\hline Diarrhoea & 08 \\
\hline
\end{tabular}

\section{DISCUSSION}

The commonly opted route for hysterectomy by most gynaecologists is the abdominal route. Thomas G Stovall et al found that the abdominal route was the approach in $70 \%$ to $80 \%$ of hysterectomies and utero-vaginal prolapse was generally an indication for vaginal approach. ${ }^{12}$ However, it is an undisputed fact that vaginal hysterectomy can easily be performed with adequate vaginal access and good uterine mobility. A partial descent can be obtained by ligating and cutting Mackenrodt's and uterosacral ligaments. The commonest reason for selecting an abdominal route for surgery is a previous pelvic surgery especially. a caesarean section. In present study we have found that up to 14 weeks size uterus with good mobility, NDVH can be done with minimal complications.

Most common indication of NDVH in present study was dysfunctional uterine bleeding (43\%) and second most common indication was fibroid $(30.5 \%)$. Shital Mehta et al, Bhadra B et al also reported DUB as a most common indication. ${ }^{13,14}$ Most common age group for non-descent vaginal hysterectomy was $40-49$ years $(65.5 \%)$. This was similar to studies of Bhadra B et al and Ray A et al. ${ }^{14,15}$.

Maximum number of cases were multiparous in present study $(87.5 \%)$. The surgery is generally easier in a multiparous woman because of laxity of ligaments, uterine mobility and roomy vagina. This was true if there was a previous vaginal delivery in present study. However, the presence of only caesarean delivery in multiparous woman did not increase the laxity of ligaments or the roominess of the vagina. These findings are similar to the study by Unger JB et al of 35 patients with previous caesarean section where presence of previous vaginal delivery improved the ease of doing an NDVH. ${ }^{16}$

Mean time for operation in this study was 58 minutes. Mean blood loss was $110 \mathrm{ml}$. No cases required blood transfusion. Operating time and blood loss were directly proportional to the size of uterus and presence of fibroid. Most of the patients were discharged within 4 days. The stay was shorter than the average stay of 5-7 days for abdominal hysterectomy in our hospital. Doucette RC et al and Magos A et al have reported an average hospital stay of 2-5 days. ${ }^{17,18}$ Nayana et al studied 10 cases of NDVH done in women with previous LSCS and had similar findings - mean duration of 50 mins with mean blood loss of $150 \mathrm{ml}$. The mean hospital stay in the study was 4 to 5 days. ${ }^{9}$

In $86 \%$ cases, additional morcellation techniques were used. This is similar to $79.74 \%$ of Bhadra B et al. ${ }^{14}$ Different techniques like bisection, bisection with enucleation of myoma and wedge resection were used in this study. There was minimal blood loss in these procedures, once bilateral uterine vessels were ligated. Different morcellation techniques could be used safely to remove vaginally fibroids up to 16 weeks size- Gimbel $\mathrm{H}$ et al. ${ }^{19} \mathrm{We}$ did not use Lash's method of coring in present study. ${ }^{20}$ We had two bladder injury in the initial phases of present study, which was recognized and repaired vaginally. Mathevet $P$ et al in a study of 3076 vaginal hysterectomies, found that the incidence of urinary and intestinal tract injuries was 1.7 and $0.5 \%$ respectively. ${ }^{21}$ Operative injuries during vaginal hysterectomy were relatively rare and could be easily recognized and treated during the initial surgery.

In present study, in five cases, we applied TVT-O/ TOT for stress urinary incontinence after doing NDVH. This was an added advantage. Operative time, blood loss, anaesthetic complications, chance of injury to bowel, bladder and ureter, bowel handling leading to paralytic ileus were minimal in present study. Shwarz R et al and Del Frat $G$ et al in their study found that the merits of vaginal approach included shorter hospital stay, fast recovery, low cost, less thrombo-embolic phenomena, less mortality and morbidity. ${ }^{22,23}$

In present study in 72 patients there was two bladder injuries due to dense adhesions and larger uterine size as compared to 03 bladder injuries by Sheth SS et al in a study of 200 patients with previous pelvic surgeries. ${ }^{24}$

\section{CONCLUSION}

Thus, present study concludes that non-descent vaginal hysterectomy is feasible, safe and efficacious for moderately enlarged uterus up to 14 weeks in a patient with previous caesarean section. Vaginal hysterectomy in a patient with previous caesarean section and a uterine size less than 14 weeks is technically challenging and 
may not increase the complication rates like conversion to laparotomy and increased blood loss. Standby operating laparoscopy provides added advantages to surgeon in cases of doubtful intra or postoperative haemostasis and to avoid laparotomy.

\section{Funding: No funding sources}

Conflict of interest: None declared

Ethical approval: The study was approved by the Institutional Ethics Committee

\section{REFERENCES}

1. Singh KC, Barman SD, Rinku Sengupta. Choice of hysterectomy for benign disease, department of obstetrics and gynaecology, university college of medical sciences, Delhi J Obstet Gynecol. 2004;54:365-70.

2. Sutton C. Hysterectomy: a historical perspective. Baillieres Clin Obstet Gynaecol. 1997;11:1-22.

3. Kovac RS. Hysterectomy outcome in patients with similar indications. J Obstet Gynecol. 2000;95:78793.

4. Silva-Filho AL, Reis FM, Noviello MB, SantosFilho AS, Cândido EB, Triginelli SA. Factors influencing the operative time and complications of vaginal hysterectomy of a nonprolapsed uterus. Female Pel Medi Reconst Surg. 2004;10:257-62.

5. Ray A, Pant L, Balsara R, Chaudhury R. Nondescent vaginal hysterectomy: a constantly improving surgical art. J Obstet Gynecol India. 2011;61:182-8.

6. Meikle SF, Nugent EW, Orleans M. Complications and recovery from laparoscopic-assisted vaginal hysterectomy compared with abdominal and vaginal hysterectomy. Obstet Gynecol.1997;89:304-11.

7. Purohit RK, Sharma JG, Singh S, Giri DK. Vaginal hysterectomy by electrosurgery for benign indications associated with previous caesarean section. J Gynecol Surg. 2013;29:7-12.

8. Rooney CM, Crawford AT, Vassallo BJ, Kleeman $\mathrm{SD}$, Karram MM. Is previous cesarean section a risk for incidental cystotomy at the time of hysterectomy?: A case-controlled study. American J Obstet Gynecol. 2005 1;193:2041-4.

9. Naina kumar, Surekha Tayade. Role of vaginal hysterectomy in previous caesarean section scar women. Int J Reprod Obstet Gynaecol. 2015;4:7859.

10. Paparella P, Sizzi O, Rossetti A, De Benedittis F, Paparella R. Vaginal hysterectomy in generally considered contraindications to vaginal surgery. Arch Gynecol Obstet. 2004;270:104-9.

11. Unger JB. Vaginal hysterectomy for the woman with moderately enlarged uterus weighing 200 to 700 grams. Am J Obstet Gynecol.1999;180:1337-44.
12. Thomas G. Stovall. Hysterectomy. Berek and Novak's Gynecology14 ${ }^{\text {th }}$ Ed. 2007;22:805.

13. Mehta ST, Trivedi YN, Bhalodia P. Role of nondescent vaginal hysterectomy in advancing gynaecological practice. J Medi Sci. 2014;3:55-8.

14. Bhadra B, Choudary AP, Tolassaria A, Nupur N. Non-Descent Vaginal hysterectomy (NDVH): Personal experiences in 158 cases. AL Ameen J Med Sci. 2011;4:23-7,

15. Ray A, Pant L, Balsara R, Chaudhury R. Nondescent vaginal hysterectomy: a constantly improving surgical art. J Obstet Gynecol India. 2011;61:182-8.

16. Unger JB, Meeks GR. Vaginal hysterectomy in women with history of previous cesarean delivery. Am J Obstet Gynecol. 1998;179:1473-8.

17. Doucette RC, Sharp HT, Alder sc. Challenging generally accepted contraindication to vaginal hysterectomy. Am J Obstet Gynecol. 2001;184:13869.

18. Magos A, Bournas N, Sinha R, Richardson RE, O'connor H. Vaginal hysterectomy for the large uterus. BJOG: Int J Obstet Gynaecol. 1996;103:24651.

19. Gimbel H, Sittnes A, Tatar A: Hysterectomy on benign indication in Denmark 1988-1998. Trend analysis: acta. Obstetrics Gynaecol Scand 2001:80:267-72.

20. Lash AF. A method for reducing the size of the uterus in vaginal hysterectomy. Am J Obstetrics Gynecol. 1941;42:452-8.

21. Mathevet P, Valencia P, Cousin C, Mellier G, Dargent D. Operative injuries during vaginal hysterectomy. European J Obstet Gynecol Reprod Biol. 2001;97:71-5.

22. Schwarz R. Choice of the surgical route in hysterectomy. Gynakologische Rundschau. 1990;30:248-52.

23. Del GF, Soligo M, Rossi A, Del CF. Vaginal and abdominal hysterectomy: comparison and perspectives. Apropos of 385 consecutive cases. Minerva ginecologica. 1996 May;48(5):181-91.

24. Sheth SS, Malpani AN. Vaginal hysterectomy following previous cesarean section. International $\mathbf{J}$ Gynecol Obstet. 1995;50:165-9.

Cite this article as: Maiti GD, Pillai A, Jose T, Lele PR. Non-descent vaginal hysterectomy in women with previous caesarean section scar: our experience. Int J Reprod Contracept Obstet Gynecol 2018;7:2404-9. 